\title{
Nature and impact of in-hospital complications associated with persistent critical illness
}

Boris Tseitkin, Johan Mårtensson, Glenn M Eastwood, Alastair Brown, Paolo Ancona, Luca Lucchetta, Theodore J Iwashyna, Raymond Robbins and Rinaldo Bellomo

www.doi.org/10.51893/2020.4.oa11

Published online first 7 December 2020

Persistent critical illness (PerCl) is a relatively novel term to describe a clinical syndrome. ${ }^{1}$ This term applies to a heterogeneous group of patients who receive prolonged intensive care unit (ICU) support and have been previously arbitrarily referred to as having "chronic" or "prolonged" critical illness. PerCl consumes a disproportionate amount of resources, ${ }^{1-4}$ presents unique challenges, and appears associated with high morbidity and mortality. ${ }^{1-3}$ Past descriptions of such patients have been variably based on either the need for organ support (eg, mechanical ventilation), ${ }^{2}$ the development of specific complications (eg, severe ICUacquired weakness), ${ }^{5}$ the timing of elective tracheostomy, ${ }^{2,3}$ or the need to remain in the ICU after the reason for admission has been treated and is no longer active. ${ }^{5}$

In a 2015 survey, ICU clinicians estimated that the transition point from acute to persistent critical illness occurs after about 10 days in the ICU. ${ }^{6}$ In support of this estimate, a large population-based retrospective multicentre observational study of over one million patients admitted to Australian and New Zealand ICUs empirically confirmed this time frame. ${ }^{1}$ Specifically, it found that beyond 10 days in the ICU (averaged across various patient subgroups), chronic pre-admission patient characteristics (age, gender and comorbidities) predicted subsequent hospital mortality more accurately than did their combined admission diagnosis and admission illness severity, as assessed by the Acute Physiology and Chronic Health Evaluation (APACHE) score. Thus, this study logically, statistically and epidemiologically defined a transition point for the onset of PerCl. However, the reasons why some patients have such prolonged ICU admissions remain unclear. In particular, it remains unknown whether these patients experience more complications, a greater rate of complications, or particular types of complications which may have contributed to a protracted ICU stay.

Accordingly, we performed a retrospective case-control study to identify, describe and quantify the prevalence, rate and nature of in-hospital complications in a cohort of PerCl

\begin{abstract}
Background: Persistent critical illness (PerCl) is defined as an intensive care unit (ICU) admission lasting $\geq 10$ days. The in-hospital complications associated with its development are poorly understood.
\end{abstract}

Aims: To test whether PerCl is associated with a greater prevalence, rate and specific types of in-hospital complications.

Methods: Single-centre, retrospective, observational casecontrol study.

Results: We studied 1200 patients admitted to a tertiary ICU from 2010 to 2015. Median ICU length of stay was 16 days (interquartile range [IQR], 12-23) for PerCl patients $v$ 2.3 days (IQR, 1.1-3.7) for controls, and median hospital length of stay was 41 days (IQR, 22-75) v 8 days (IQR, 4-17) respectively. A greater proportion of $\mathrm{PerCl}$ patients received acute renal replacement therapy (37\% $\vee 6.8 \%)$ or underwent reintubation (17\% $\vee 1 \%)$ and/or tracheostomy $(36 \% \vee 0.6 \%) ; P<0.0001$. Despite these complications, PerCl patients had similar hospital mortality (29\% v 27\%; $P=0.53)$. PerCl patients experienced a greater absolute number of complications (12.1 $v 4.0$ complications per patient; $P<0.0001$ ) but had fewer exposure-adjusted complications (202 v 272 complications per 1000 hospital bed-days; $P<0.001$ ) and a particularly high overall prevalence of specific complications.

Conclusions: PerCl patients experience a higher prevalence, but not a higher rate, of exposure-adjusted complications. Some of these complications appear amenable to prevention, helping to define intervention targets in patients at risk of PerCl.

Funding: Austin Hospital Intensive Care Trust Fund.

Crit Care Resusc 2020; 22 (4): 378-387 


\section{ORIGINAL ARTICLES}

patients treated in a university-affiliated tertiary hospital in comparison with a cohort of matched controls. Specifically, we aimed to test the hypothesis that PerCl patients would experience more complications in general, a greater rate of complications per 1000 hospital bed-days, and a specific set of complications compared with control patients.

\section{Methods}

\section{Study design and patients}

We performed a single-centre retrospective case-control study using existing electronic databases and patient records of a university-affiliated tertiary referral hospital in Melbourne, Australia. The Austin Hospital's Human Research Ethics Committee, approved the study (approval No. LNR/16/Austin/402), with a waiver of informed consent.

We retrieved discharge coding data for all ICU admissions over the 5-year period between August 2010 and September 2015. We identified PerCl patients in this dataset as those with an ICU length of stay greater than 10 days (240 hours). We cross-referenced coding data with corresponding entries in the hospital's subset of the Australia and New Zealand Intensive Care Society Adult Patient Database ${ }^{7}$ to enhance data completeness and integrity. We considered only the first ICU admission during a given hospital stay. We identified a PerCl cohort of 300 cases. PerCl patients were then matched in a 1:3 ratio, with 900 controls from the same dataset, based on four matching categories: age $(<50,50-64,65-74$ and $>74$ years), APACHE III score $(<40$, 40-49, 50-64, > 64), mechanical ventilation (yes $v$ no) and admission diagnosis type (operative $v$ non-operative). We confined our control group to patients with an ICU length of stay less than 6 days (144 hours) to create adequate cohort separation.

For these PerCl cases and controls, we compared baseline patient characteristics; process of care, major complications, outcomes and disposition; and admission diagnoses, grouped by organ system.

To better understand whether complications were attributable to ICU admission or the underlying illness, in a sensitivity analysis, we compared baseline patient characteristics (Online appendix, table S2) and complications (Online appendix, table S3) between patients who were admitted to the ICU on the same day they presented to hospital and patients who were admitted to the ICU one or more days after presenting to hospital.

We recognised that by definition, $\mathrm{PerCl}$ can only occur in patients in the ICU who have not died before 10 days; thus, controls who die before 10 days are not at risk of developing $\mathrm{PerCl}$. Therefore, in an additional sensitivity analysis, we identified controls with an equivalent minimum survival time to PerCl patients (ie, those who survived a minimum of 10 days) by removing controls with a hospital length of stay less than 7 days since ICU admission and controls who died following a hospital length of stay of 7-10 days since ICU admission. We compared PerCl patients to these survivors beyond 10 days for baseline patient characteristics (Online appendix, table S4); process of care, major complications, outcomes and disposition (Online appendix, table S5); complication rate per 1000 hospital bed-days (Online appendix, table S6); complications according to the Classification of Hospital-Acquired Diagnoses (CHADx) diagnostic categories (Online appendix, table S7); and finally, complications according to CHADx diagnostic categories adjusted for exposure time (Online appendix, table S8).

Furthermore, since there was no information on the timing and severity of complications in our original dataset, we targeted a nested cohort for additional detailed analysis. We did this by randomly sampling 10\% (30 cases and 90 controls) from the original dataset of 300 cases and 900 controls to explore their complications in greater detail.

We validated this nested cohort as a representative sample of the entire dataset by comparing their baseline patient characteristics (Online appendix, table S9). We reviewed the nested cohort patients' medical records at length to ascertain the timing of each complication (before, during or after ICU admission) and to create a severity association, by means of assessing its contribution to adverse outcomes (eg, to further complications, rescue interventions, impact on length of stay, and mortality).

We defined complications as all diagnoses not present on admission, coded by trained hospital coders following patient discharge, expressed in the International Classification of Diseases, tenth revision, Australian modification (ICD-10AM) format ${ }^{8}$ and classified according to $\mathrm{CHADx} .{ }^{9}$ CHADx is a statistical tool developed in Australia for use within hospitals, the purpose of which is to help monitor the range of hospital-acquired diagnoses coded in routine data in support of quality improvement efforts. ${ }^{10}$ In addition, as part of our analysis, we adjusted these complications for exposure time (per 1000 hospital bed-days).

\section{Statistical analysis}

We summarised continuous data as medians (interquartile range $[I Q R])$ and compared them using the Mann-Whitney $U$ test. We summarised categorical data as numbers (percentages) and compared them using the $\chi^{2}$ test or Fisher exact test.

We reported complications as the number per patient, with $95 \%$ confidence intervals (Cls). We also reported the number of complications per 1000 hospital bed-days (complication rate). We compared the mean number of complications between cases and controls using Poisson regression analysis. We performed analyses using STATA 


\section{ORIGINAL ARTICLES}

version 11.2 (Stata, College Station, TX). We considered two-sided $P<0.01$ as statistically significant to adjust for multiple comparisons.

\section{Results}

We studied $300 \mathrm{PerCl}$ patients and 900 controls admitted between August 2010 and September 2015 (Figure 1).

\section{Patient characteristics}

Table 1 shows key patient characteristics at baseline. PerCl patients had lower rates of ICU admission on the same day as hospital admission and higher Charlson Comorbidity Index scores. They also had a higher average serum creatinine and white cell count but a lower albumin level on the day of admission. Although well matched for operative versus non-operative admission (31\% $\vee 33 \% ; P=0.53$ ), PerCl patients had significantly different diagnostic categories on hospital admission (Online appendix, table S1). Controls who survived beyond 10 days (Online appendix, table S4) were older than $\mathrm{PerCl}$ patients and had more operative admission diagnoses; similar to the broader control group, they had lower rates of cardiovascular disease and lower creatinine and white cell count than PerCl patients.

\section{Process of care, major complications, outcomes and disposition}

Table 2 shows selected major ICU interventions, discharge destination, and mortality. As expected, based on our a priori definitions, PerCl patients had significantly longer ICU and hospital lengths of stay than controls, and spent longer on mechanical ventilation. In absolute terms, PerCl patients were five times more likely to undergo renal replacement therapy, 17 times more likely to be reintubated, and 60 times more likely to receive a tracheostomy $(P<0.0001$ for all comparisons). They were also more likely to have multiple body systems affected during their hospital stay, signifying more multi-organ failure.

PerCl patients had significantly lower ICU mortality $(P=0.022)$, but a similar hospital mortality $(P=0.53)$, than control patients. However, a smaller proportion of PerCl patients than controls were discharged directly home $(P=0.002)$. Comparing PerCl patients with controls who survived beyond 10 days (Online appendix, table S5) was largely analogous to the broader control group, with the exception of zero ICU mortality (ICU deaths were excluded).

After adjustment for exposure time (per 1000 hospital bed-days, Table 3), the rates of renal replacement therapy, reintubation and tracheostomy were still significantly higher in PerCl patients. By contrast, the rates of other common complications (delirium and agitation, pressure injuries, sepsis and pneumonia) were similar in controls and PerCl patients ( $P=0.04-0.97)$, while rates of hypotension and acute kidney injury were actually higher in controls $(P<0.001)$. Similarly, in comparison to controls who survived beyond 10 days (Online appendix, table S6), PerCl patients still had higher rates of renal replacement therapy, reintubation, tracheostomy and, additionally, sepsis; however, they also had lower rates of hypotension ( $P<0.001$ for all comparisons), and no significant difference in other complications between the groups.

\section{Complications}

Table 4 shows the in-hospital complications of $\mathrm{PerCl}$ patients and controls, classified by 


\section{ORIGINAL ARTICLES}

Table 1. Baseline patient characteristics

\begin{tabular}{|c|c|c|c|}
\hline Characteristic & $\begin{array}{l}\text { Cases } \\
(n=300)\end{array}$ & $\begin{array}{l}\text { Controls } \\
(n=900)\end{array}$ & $P$ \\
\hline Age (years), median (IQR) & $62(51-73)$ & $63(50-73)$ & 0.441 \\
\hline Male sex & $185(62.4 \%)$ & $564(62.7 \%)$ & 0.757 \\
\hline APACHE III score, median (IQR) & $70(57-91)$ & $71(56-93)$ & 0.517 \\
\hline $\begin{array}{l}\text { ICU admission on the same day as } \\
\text { hospital admission }\end{array}$ & $156(52.0 \%)$ & $552(61.3 \%)$ & 0.004 \\
\hline Operative admission diagnosis & $92(31.3 \%)$ & $297(33.3 \%)$ & 0.53 \\
\hline Emergency admission & $222(74.0 \%)$ & $653(72.6 \%)$ & 0.626 \\
\hline \multicolumn{4}{|l|}{ Charlson Comorbidity Index score } \\
\hline 0 & $66(22.0 \%)$ & $287(31.9 \%)$ & 0.001 \\
\hline $1-2$ & $111(37.0 \%)$ & $334(37.1 \%)$ & \\
\hline$>2$ & $123(41.0 \%)$ & $279(31.0 \%)$ & \\
\hline \multicolumn{4}{|l|}{ Comorbidity } \\
\hline Immune disease & $21(7.0 \%)$ & $54(6.0 \%)$ & 0.535 \\
\hline Immunosuppressed & $20(6.7 \%)$ & $56(6.2 \%)$ & 0.784 \\
\hline Chronic liver disease & $31(10.3 \%)$ & $100(11.1 \%)$ & 0.708 \\
\hline Metastases & $5(1.7 \%)$ & $40(4.4 \%)$ & 0.028 \\
\hline Leukemia/myeloma & $6(2.0 \%)$ & $14(1.6 \%)$ & 0.603 \\
\hline Insulin-dependent diabetes & $9(3.0 \%)$ & $12(1.3 \%)$ & 0.057 \\
\hline Respiratory disease & $14(4.7 \%)$ & $31(3.4 \%)$ & 0.335 \\
\hline Cardiovascular disease & $12(4.0 \%)$ & $15(1.7 \%)$ & 0.018 \\
\hline Lymphoma & $4(1.3 \%)$ & $9(1.0 \%)$ & 0.629 \\
\hline Chronic renal failure & $13(4.3 \%)$ & $33(3.7 \%)$ & 0.602 \\
\hline \multicolumn{4}{|l|}{ Baseline biochemistry, median (IQR) } \\
\hline Creatinine, mmol/L & $123(78-211)$ & $102(75-152)$ & 0.0003 \\
\hline Albumin, g/L & $26(21-30)$ & $28(23-32)$ & 0.0001 \\
\hline White cell count, $\times 10^{9} / \mathrm{L}$ & $15(10-20)$ & $13(9.3-18)$ & 0.002 \\
\hline Mechanical ventilation & $290(96.7 \%)$ & $872(96.9 \%)$ & 0.85 \\
\hline
\end{tabular}

APACHE = Acute Physiology and Chronic Health Evaluation; ICU = intensive care unit; IQR = interquartile range.

CHADx diagnostic category. For all types of complications except accidental injuries, $\mathrm{PerCl}$ patients experienced a greater number of complications per patient. In five CHADx diagnostic categories (post-procedural, cardiovascular, respiratory, gastrointestinal and metabolic), the average number of complications exceeded one per PerCl admission. Moreover, a greater proportion of PerCl patients experienced at least one (any) complication. Similarly, compared with controls who survived at least 10 days, PerCl patients experienced a greater number of complications per patient in all categories except accidental injuries and adverse drug events (Online appendix, table S7).

Table 5 shows the same CHADx diagnostic categories of in-hospital complications for PerCl patients and controls, adjusted for exposure time (per 1000 hospital bed-days). In contrast to the unadjusted analysis, after adjustment for exposure time PerCl patients had a significantly lower complication rate (events per 1000 hospital bed-days) than controls in most diagnostic categories, while controls who survived at least 10 days had mixed outcomes, with higher rates of adverse drug events; cardiovascular, respiratory and metabolic complications $(P<0.01)$; lower rates of infections and neurological complications; and similar rates of other complications as PerCl patients (Online appendix, table S8).

A detailed list of all complications coded for our entire cohort is available in the Online appendix, table 59. The most prevalent coded in-hospital complications in PerCl patients were hypotension, delirium, acute kidney injury, pressure injuries, electrolyte derangement, and sepsis with or without septic shock (Figure 2).

In our sensitivity analysis comparing patients admitted to ICU on day one versus patients admitted after day one (Online appendix, tables S2 and S3), we found the only significant differences in baseline characteristics between these groups were lower Charlson Comorbidity Index scores $(P<0.001)$ and shorter ICU length of stay (median $2.8 \vee 3.5$ days; $P=0.002$ ) in patients admitted to the ICU on the day of hospital admission. However, experiencing at least one (any) complication was significantly more common $(91.9 \% \vee 81.5 \% ; P<0.0001)$ in patients admitted to the ICU on subsequent days. In ten of $13 \mathrm{CHADx}$ diagnostic categories, complications were more prevalent in patients admitted to the ICU on subsequent days $(P<0.01)$, suggesting that these complications may have occurred before ICU admission. There was no significant difference in the remaining three CHADx diagnostic categories.

\section{Nested cohort}

Comparison of baseline characteristics between the full and nested cohorts (Online appendix, table S10) demonstrates that the nested cohort was a valid and representative 


\section{ORIGINAL ARTICLES}

\begin{tabular}{|c|c|c|c|}
\hline Variable & $\begin{array}{c}\text { Cases } \\
(n=300)\end{array}$ & $\begin{array}{l}\text { Controls } \\
(n=900)\end{array}$ & $P$ \\
\hline Mechanical ventilation (hours), median (IQR) & $260(171-411)$ & $19(9-43)$ & $<0.0001$ \\
\hline Non-invasive ventilation & $7(2.3 \%)$ & $6(0.7 \%)$ & 0.016 \\
\hline Renal replacement therapy & $111(37.0 \%)$ & $61(6.8 \%)$ & $<0.0001$ \\
\hline Reintubation & $52(17.3 \%)$ & $9(1.0 \%)$ & $<0.0001$ \\
\hline Tracheostomy & $109(36.3 \%)$ & $5(0.6 \%)$ & $<0.0001$ \\
\hline IABP & $11(3.7 \%)$ & $19(2.1 \%)$ & 0.135 \\
\hline ECMO & $3(1.0 \%)$ & $2(0.2 \%)$ & 0.103 \\
\hline ICU LOS (days), median (IQR) & $16(12-23)$ & $2.3(1.1-3.7)$ & $<0.0001$ \\
\hline Hospital LOS (days), median (IQR) & $41(22-75)$ & $8(4-17)$ & $<0.0001$ \\
\hline \multicolumn{4}{|l|}{ Hospital separation mode } \\
\hline Deceased & $88(29.3 \%)$ & $247(27.4 \%)$ & 0.53 \\
\hline Home & $156(52.0 \%)$ & $561(62.3 \%)$ & 0.002 \\
\hline \multicolumn{4}{|l|}{ ICU mortality } \\
\hline Yes & $49(16.3 \%)$ & $205(22.8 \%)$ & 0.022 \\
\hline No & $245(81.7 \%)$ & $687(76.3 \%)$ & \\
\hline Unknown & $6(2.0 \%)$ & $8(0.9 \%)$ & \\
\hline \multicolumn{4}{|l|}{ Number of body systems* affected } \\
\hline $1-4$ & $13(4.3 \%)$ & $360(40.0 \%)$ & $<0.0001$ \\
\hline $5-8$ & $96(32.0 \%)$ & $440(48.9 \%)$ & \\
\hline$>8$ & $191(63.7 \%)$ & $100(11.1 \%)$ & \\
\hline
\end{tabular}

$\mathrm{ECMO}=$ extra-corporeal membrane oxygenation; $\mathrm{IABP}=$ intra-aortic counter-pulsation balloon pump; ICU = intensive care unit; LOS = length of stay. * Defined by the International Classification of Diseases, tenth revision, Australian modification (ICD-10-AM) chapters coded as principal and secondary diagnoses.

Following adjustment for exposure time of only those complications that occurred during the ICU admission (Online appendix, table S11.2), the rates of acute kidney injury and hypotension became significantly higher in controls than in PerCl patients $(P<0.001)$, with similar rates of all other complications. Combined totals of complications before, during and after ICU admission showed no significant difference for any of the complications in our nested cohort.

\section{Discussion}

\section{Key findings}

We studied the in-hospital complications of a 300-patient cohort of $\mathrm{PerCl}$ patients and a 900-patient cohort of controls. We found that PerCl was associated with a threefold greater absolute number of complications. Moreover, a markedly higher proportion of PerCl patients underwent major ICU interventions including

sample. In particular, demographics; severity of disease (APACHE scores); direct, post-operative and emergency ICU admissions; and ICU length of stay were similar.

A detailed review of the complications coded for nested cohort PerCl patients and controls, respectively, is presented in the Online appendix, tables S12 and S13.

Table S11.1 in the Online appendix describes the most prevalent complications in our nested cohort, compares the proportions of affected cases and controls, and illustrates the timing of their onset relative to ICU admission. Tracheostomy malfunction during ICU admission was significantly more common in PerCl patients $(P=0.01)$. There were no significant differences in any other procedural complications, either before, during or after ICU admission. Delirium, pneumonia, pressure injuries, and electrolyte, fluid or acid-base disturbances were significantly more common in PerCl patients $(P<0.01)$, all during their ICU admission, again with no significant differences in other non-procedural complications, nor in the period before or after ICU admission. reintubation, tracheostomy and acute renal replacement therapy, with the rates of these major ICU interventions remaining significantly higher after adjustment for exposure time. Hypotension, delirium and agitation, acute kidney injury, sepsis, pneumonia, pressure injuries, and metabolic and electrolyte abnormalities were the most commonly documented complications. Hospital mortality was similar in the two groups, but a smaller proportion of PerCl patients were discharged directly home from hospital.

\section{Relationship to previous findings}

To our knowledge, this is the first study to explicitly report complications associated with PerCl. Previous studies using variable definitions of this syndrome did not address the inhospital complications or diagnoses.

For example, Mira and colleagues ${ }^{11}$ identified greater shock severity more frequent organ failures, and more infectious complications in long-stay ICU patients with trauma. Similarly, Ambrosino et $\mathrm{al}^{12}$ and Nelson et $\mathrm{al}^{4}$ discussed musculoskeletal (myopathy, neuropathy) ${ }^{13}$ and 


\section{ORIGINAL ARTICLES}

Table 3. Complications (rate per patient, adjusted per 1000 hospital bed-days)

\begin{tabular}{|c|c|c|c|c|c|c|}
\hline \multirow[b]{2}{*}{ Complication } & \multicolumn{2}{|c|}{$\begin{array}{c}\text { Cases } \\
(n=300)\end{array}$} & \multicolumn{2}{|c|}{$\begin{array}{l}\text { Controls } \\
(n=900)\end{array}$} & \multirow[b]{2}{*}{$\begin{array}{c}\text { Rate difference* } \\
(95 \% \mathrm{Cl})\end{array}$} & \multirow[b]{2}{*}{$P^{\dagger}$} \\
\hline & $\begin{array}{c}\text { Rate } \\
(95 \% \mathrm{Cl})\end{array}$ & $\begin{array}{l}\text { Number } \\
\text { of events }\end{array}$ & $\begin{array}{c}\text { Rate } \\
(95 \% \mathrm{Cl})\end{array}$ & $\begin{array}{l}\text { Number } \\
\text { of events }\end{array}$ & & \\
\hline $\begin{array}{l}\text { Total number of } \\
\text { hospital bed-days }\end{array}$ & 17890 & & 13342 & & & \\
\hline \multicolumn{7}{|l|}{$\begin{array}{l}\text { Complications per } \\
1000 \text { hospital bed- } \\
\text { days }\end{array}$} \\
\hline \multicolumn{7}{|l|}{ Renal replacement } \\
\hline therapy ${ }^{\ddagger}$ & $5.7(4.6-6.9)$ & 98 & $2.2(1.4-3.1)$ & 28 & $3.5(2.1-5.0)$ & $<0.001$ \\
\hline Reintubation & $2.9(2.2-3.8)$ & 52 & $0.7(0.3-1.3)$ & 9 & $2.2(1.2-3.2)$ & $<0.001$ \\
\hline Tracheostomy & $6.1(5.0-7.3)$ & 109 & $0.4(0.1-0.9)$ & 5 & $5.7(4.4-7.1)$ & $<0.001$ \\
\hline Hypotension & $7.2(6.0-8.5)$ & 128 & $19.8(17.5-22.3)$ & 264 & $-12.6(-15.1$ to -10.1$)$ & $<0.001$ \\
\hline Delirium & $6.9(5.7-8.2)$ & 123 & $6.8(5.5-8.4)$ & 91 & $0.1(-1.8$ to 1.9$)$ & 0.96 \\
\hline $\begin{array}{l}\text { Restlessness and } \\
\text { agitation }\end{array}$ & $2.5(1.8-3.3)$ & 44 & $3.0(2.1-4.1)$ & 40 & $-0.5(-1.7$ to 0.6$)$ & 0.37 \\
\hline $\begin{array}{l}\text { Acute kidney } \\
\text { injury }\end{array}$ & $6.6(5.5-7.9)$ & 118 & $10.0(8.4-11.9)$ & 134 & $-3.4(-5.5$ to -1.4$)$ & $<0.001$ \\
\hline Pressure injuries & $5.0(4.0-6.1)$ & 89 & $3.4(2.5-4.6)$ & 46 & $1.5(0.1-3.0)$ & 0.04 \\
\hline $\begin{array}{l}\text { Sepsis and septic } \\
\text { shock (all) }\end{array}$ & $7.0(5.8-8.3)$ & 125 & $6.1(4.9-7.6)$ & 82 & $0.8(-1.0$ to 2.7$)$ & 0.37 \\
\hline Pneumonia (all) & $6.9(5.8-8.3)$ & 124 & $6.9(5.6-8.5)$ & 92 & $0.04(-1.8$ to 1.9$)$ & 0.97 \\
\hline
\end{tabular}

* The "rate difference" is the difference between cases (patients with persistent critical illness [PerCI]) and controls in the rate of events per patient per 1000 hospital bed-days. A negative rate difference, as seen above, means that controls had higher event rates than PerCl patients, or in other words, more complications when adjusted for exposure time. $+P$ is derived using uncorrected Pearson $\chi^{2}$ test and compares the proportion of patients with at least one complication. \# Patients with end-stage renal disease excluded. Number of hospital bed-days for patients without end-stage renal disease was 17211 in cases and 12928 in controls.

neuroendocrine problems (protein catabolism), ${ }^{14}$ increased vulnerability to multiresistant infections, ${ }^{15,16}$ prolonged coma and delirium, ${ }^{17}$ and skin breakdown associated with nutritional deficiencies, oedema and incontinence. ${ }^{18}$ Schulman and colleagues ${ }^{19}$ conceived a distinct metabolic state of chronic critical illness, bearing a wide constellation of features similar to Ambrosino et al, ${ }^{12}$ with the addition of stress-induced hyperglycaemia, ${ }^{20,21}$ bone hyper-resorption and vitamin $D$ deficiency, 22 and excessive symptom burden including pain and distress. ${ }^{23}$ Girard $^{24}$ focused on acute neurocognitive dysfunction in the form of coma or delirium and its short term adverse outcomes, including prolonged hospitalisation, increased health care costs and mortality, as well as long term memory deficits and executive dysfunction. However, none of the above studies comprehensively assessed a wide variety of complications, adjusted the number of complications according to duration of exposure, or compared the prevalence, rate and nature of such complications to a matched control group.

\section{Implications of study findings}

Our findings establish that although $\mathrm{PerCl}$ patients experience more complications, their overall complication rate is similar or lower than that of matched controls, when less severe complications are considered. This observation implies that these complications are a less likely explanation for PerCl than the original illness process leading to its development, and that the nature, severity and duration of the complications may be of greater impact than their occurrence.

Alternatively, they may imply that, rather than any special predisposition to $\mathrm{PerCl}$ of those patients who eventually develop it, ICU physicians are equally or more efficacious at treating complications that are ICU-acquired (sometimes known as rescue $)^{25}$ than they are at treating similar problems when patients present with them. Moreover, the similar mortality rate experienced by PerCl patients despite prolonged ICU stay suggests that ICU care may have helped 
Table 4. Complications according to Classification of Hospital-Acquired Diagnoses (CHADx) diagnostic categories

\begin{tabular}{|c|c|c|c|c|c|c|c|c|}
\hline \multirow[b]{2}{*}{ Complication* } & \multicolumn{3}{|c|}{$\begin{array}{c}\text { Cases } \\
(n=300)\end{array}$} & \multicolumn{3}{|c|}{ Controls $(n=900)$} & \multirow[b]{2}{*}{$P^{\dagger}$} & \multirow[b]{2}{*}{$P^{\ddagger}$} \\
\hline & $\begin{array}{c}\text { Number of } \\
\text { events per } \\
\text { patient } \\
(95 \% \mathrm{Cl})\end{array}$ & $\begin{array}{l}\text { Num- } \\
\text { ber of } \\
\text { events }\end{array}$ & $\begin{array}{c}\text { Number of } \\
\text { patients } \\
(\%)\end{array}$ & $\begin{array}{c}\text { Number of } \\
\text { events per } \\
\text { patient } \\
(95 \% \mathrm{Cl})\end{array}$ & $\begin{array}{l}\text { Num- } \\
\text { ber of } \\
\text { events }\end{array}$ & $\begin{array}{c}\text { Number of } \\
\text { patients } \\
(\%)\end{array}$ & & \\
\hline Post-procedural & $1.10(0.98-1.23)$ & 330 & $164(54.7 \%)$ & $0.35(0.31-0.39)$ & 311 & $\begin{array}{c}224 \\
(24.9 \%)\end{array}$ & $<0.0001$ & $<0.0001$ \\
\hline $\begin{array}{l}\text { Adverse drug } \\
\text { events }\end{array}$ & $0.26(0.20-0.32)$ & 77 & $57(19.0 \%)$ & $0.14(0.11-0.16)$ & 122 & $94(10.4 \%)$ & 0.002 & $<0.0001$ \\
\hline $\begin{array}{l}\text { Accidental } \\
\text { injuries }\end{array}$ & $0.04(0.02-0.07)$ & 13 & $13(4.3 \%)$ & $0.03(0.02-0.05)$ & 30 & $30(3.3 \%)$ & 0.485 & 0.420 \\
\hline $\begin{array}{l}\text { Specific } \\
\text { infections }\end{array}$ & $0.75(0.66-0.85)$ & 225 & $141(47.0 \%)$ & $0.14(0.12-0.17)$ & 126 & $96(10.7 \%)$ & $<0.0001$ & $<0.0001$ \\
\hline Cardiovascular & $1.68(1.53-1.83)$ & 503 & $232(77.3 \%)$ & $0.77(0.71-0.83)$ & 691 & $\begin{array}{c}435 \\
(48.3 \%)\end{array}$ & $<0.0001$ & $<0.0001$ \\
\hline Respiratory & $1.41(1.28-1.55)$ & 424 & $215(71.7 \%)$ & $0.51(0.46-0.56)$ & 458 & $\begin{array}{c}312 \\
(34.7 \%)\end{array}$ & $<0.0001$ & $<0.0001$ \\
\hline Gastrointestinal & $1.03(0.92-1.15)$ & 308 & $181(60.3 \%)$ & $0.25(0.21-0.28)$ & 221 & $\begin{array}{c}169 \\
(18.8 \%)\end{array}$ & $<0.0001$ & $<0.0001$ \\
\hline Genitourinary & $0.79(0.70-0.90)$ & 238 & $168(56.0 \%)$ & $0.29(0.25-0.32)$ & 258 & $\begin{array}{c}201 \\
(22.3 \%)\end{array}$ & $<0.0001$ & $<0.0001$ \\
\hline Psychiatric & $0.78(0.68-0.89)$ & 234 & $170(56.7 \%)$ & $0.24(0.21-0.27)$ & 213 & $\begin{array}{c}176 \\
(19.6 \%)\end{array}$ & $<0.0001$ & $<0.0001$ \\
\hline Haematological & $0.66(0.57-0.76)$ & 199 & $144(48.0 \%)$ & $0.22(0.19-0.25)$ & 197 & $\begin{array}{c}157 \\
(17.4 \%)\end{array}$ & $<0.0001$ & $<0.0001$ \\
\hline Metabolic & 1.74 (1.59-1.89) & 521 & $241(80.3 \%)$ & $0.64(0.59-0.69)$ & 575 & $\begin{array}{c}360 \\
(40.0 \%)\end{array}$ & $<0.0001$ & $<0.0001$ \\
\hline Neurological & $0.28(0.22-0.34)$ & 83 & $61(20.3 \%)$ & $0.08(0.06-0.10)$ & 69 & $59(6.6 \%)$ & $<0.0001$ & $<0.0001$ \\
\hline Other & $0.93(0.82-1.05)$ & 279 & $151(50.3 \%)$ & $0.27(0.24-0.30)$ & 242 & $\begin{array}{c}191 \\
(21.2 \%)\end{array}$ & $<0.0001$ & $<0.0001$ \\
\hline $\begin{array}{l}\text { Any } \\
\text { complication }\end{array}$ & $12.1(11.7-12.5)$ & 3621 & $295(98.3 \%)$ & $4.0(3.9-4.2)$ & 3627 & $\begin{array}{c}734 \\
(81.6 \%)\end{array}$ & $<0.0001$ & $<0.0001$ \\
\hline
\end{tabular}

* The categories in this column correspond to CHADx diagnostic categories where discharge diagnoses were coded. These, in turn, relate to the body system applicable to the International Classification of Diseases, tenth revision, Australian modification (ICD-10-AM) diagnosis. $+P$ is derived using Poisson regression and refers to the comparison of mean number of events per patient. $\neq P$ is derived using uncorrected Pearson $\chi^{2}$ test and compares the proportion of patients with at least one complication.

rescue such patients from the immediate consequences of severe illness.

Finally, our observations imply that, despite the above considerations, some complications may be particularly common in $\mathrm{PerCl}$ patients and are therefore the logical focus of intervention, alongside currently recognised management strategies. ${ }^{26}$

\section{Study strengths and limitations}

Our study has several strengths. It is the first study of PerCl using a matched control cohort, and the first to focus on associated complications, including adjusting these for exposure time. We utilised the new, empirical definition of PerCl, derived from over a million ICU patients, which bears substantial face and content validity. We used a systematic approach to the definition of complications, which has been previously published and was not amenable to bias, having been identified by trained hospital coders before analysis. Our study sampled a large database containing detailed clinical information, with external validity of findings demonstrated by comparable patient outcomes in our cohort to Iwashyna and colleagues'1 populationbased outcomes (hospital mortality $29 \% \vee 25 \%$, rates 


\section{ORIGINAL ARTICLES}

Table 5. Complications according to Classification of Hospital-Acquired Diagnoses (CHADx) diagnostic categories (rate per patient, adjusted per 1000 hospital bed-days)

\begin{tabular}{|c|c|c|c|c|c|c|}
\hline \multirow[b]{2}{*}{ Complication } & \multicolumn{2}{|c|}{$\begin{array}{c}\text { Cases } \\
(n=300)\end{array}$} & \multicolumn{2}{|c|}{$\begin{array}{l}\text { Controls } \\
(n=900)\end{array}$} & \multirow[b]{2}{*}{$\begin{array}{l}\text { Rate difference* } \\
(95 \% \mathrm{Cl})\end{array}$} & \multirow[b]{2}{*}{$P^{+}$} \\
\hline & $\begin{array}{c}\text { Rate } \\
(95 \% \mathrm{Cl})\end{array}$ & $\begin{array}{c}\text { Number of } \\
\text { events }\end{array}$ & $\begin{array}{c}\text { Rate } \\
(95 \% \mathrm{Cl})\end{array}$ & $\begin{array}{c}\text { Number of } \\
\text { events }\end{array}$ & & \\
\hline $\begin{array}{l}\text { Total number of hospital } \\
\text { bed-days }\end{array}$ & 17890 & & 13342 & & & \\
\hline \multicolumn{7}{|l|}{$\begin{array}{l}\text { Complications per } 1000 \\
\text { hospital bed-days }\end{array}$} \\
\hline Post-procedural & $18(17-21)$ & 330 & $23(21-26)$ & 311 & $-5(-8$ to -2$)$ & 0.003 \\
\hline Adverse drug events & $4(3-5)$ & 77 & $9(8-11)$ & 122 & $-5(-7$ to -3$)$ & $<0.001$ \\
\hline Accidental injuries & $1(0.4-1.2)$ & 13 & $2(1.5-3)$ & 30 & $-1.5(-2.4$ to -0.7$)$ & $<0.001$ \\
\hline Specific infections & $13(11-14)$ & 225 & $9(8-11)$ & 126 & $3(0.8-6)$ & 0.01 \\
\hline Cardiovascular & $28(26-31)$ & 503 & $52(48-56)$ & 691 & $-24(-28$ to -19$)$ & $<0.001$ \\
\hline Respiratory & $24(21-26)$ & 424 & $34(31-38)$ & 458 & $-11(-14$ to -7$)$ & $<0.001$ \\
\hline Gastrointestinal & $17(15-19)$ & 308 & $17(14-19)$ & 221 & 0.7 (-2 to 4$)$ & 0.66 \\
\hline Genitourinary & $13(12-15)$ & 238 & $19(17-22)$ & 258 & $-6(-9$ to -3$)$ & $<0.001$ \\
\hline Psychiatric & $13(11-15)$ & 234 & $16(14-18)$ & 213 & $-3(-6$ to -0.2$)$ & 0.04 \\
\hline Haematological & $11(10-13)$ & 199 & $15(13-17)$ & 197 & $-4(-6$ to -1$)$ & 0.005 \\
\hline Metabolic & $29(27-32)$ & 521 & $43(40-47)$ & 575 & $-14(-18$ to -10$)$ & $<0.001$ \\
\hline Neurological & $5(4-6)$ & 83 & $5(4-7)$ & 69 & $-0.5(-2$ to 1$)$ & 0.51 \\
\hline Other & $16(14-18)$ & 279 & $18(16-21)$ & 242 & $-3(-5$ to 0.4$)$ & 0.09 \\
\hline Any complication & 202 (196-209) & 3621 & $272(263-281)$ & 3627 & $-69(-80$ to -59$)$ & $<0.001$ \\
\hline
\end{tabular}

* The "rate difference" is the difference between cases (patients with persistent critical illness [PerCI]) and controls in the rate of events per patient per 1000 hospital bed-days. A negative rate difference, as seen above, means that controls had higher event rates than PerCl patients, or in other words, more complications when adjusted for exposure time. $+P$ is derived using uncorrected Pearson $\chi^{2}$ test and compares the proportion of patients with at least one complication.

of discharge home $52 \% \vee 47 \%$ ), and to Damuth and colleagues'27 meta-analysis with a similar in-hospital mortality rate $(29 \% \vee 31 \%)$.

Our study has certain limitations. It is single-centre and retrospective, with the inherent limitations of such studies. However, these exploratory analyses are the necessary first step to identify the focus of prospective future studies. During data collection for our nested cohort, we identified a variety of missing data - some clinical events, diagnoses and deranged pathology results were documented in the medical record but omitted from being coded as complications. However, these missing data did not appear to materially alter our findings. Some of the data extracted from our original dataset, such as rates of comorbid respiratory and cardiovascular disease, were unexpectedly low, suggesting deficiencies of clinical coding. Data on goals of patient care or resuscitation status were not collected as part of our nested cohort, nor available in our original dataset.
Further, CHADx requires the collection of a condition present on admission (CPOA) variable. If a condition was not present on admission, it was deemed to have been hospitalacquired. Using the CPOA variable as a surrogate marker, the potential error rate within CHADx has been estimated at up to a quarter. It is therefore possible that CHADx underestimates the true prevalence of complications by up to a quarter, in addition to complications not coded due to missing data and to CHADx's reliance on ICD-10-AM diagnoses, which may also be absent or mislabelled.

The difference in complication rates for some less clinically important events may also reflect documentation bias, ascertainment bias, and clinical relevance bias. Thus, for example, hypotension may be noted as an adverse event and documented as such differently when the patient is in the ICU receiving vasopressor support (in effect, preventing or masking it) compared with outside the ICU where its occurrence triggers a reaction, documentation and CHADx 


\section{ORIGINAL ARTICLES}

\section{Figure 2. Histogram presenting the most common complications associated with persistent critical illness}

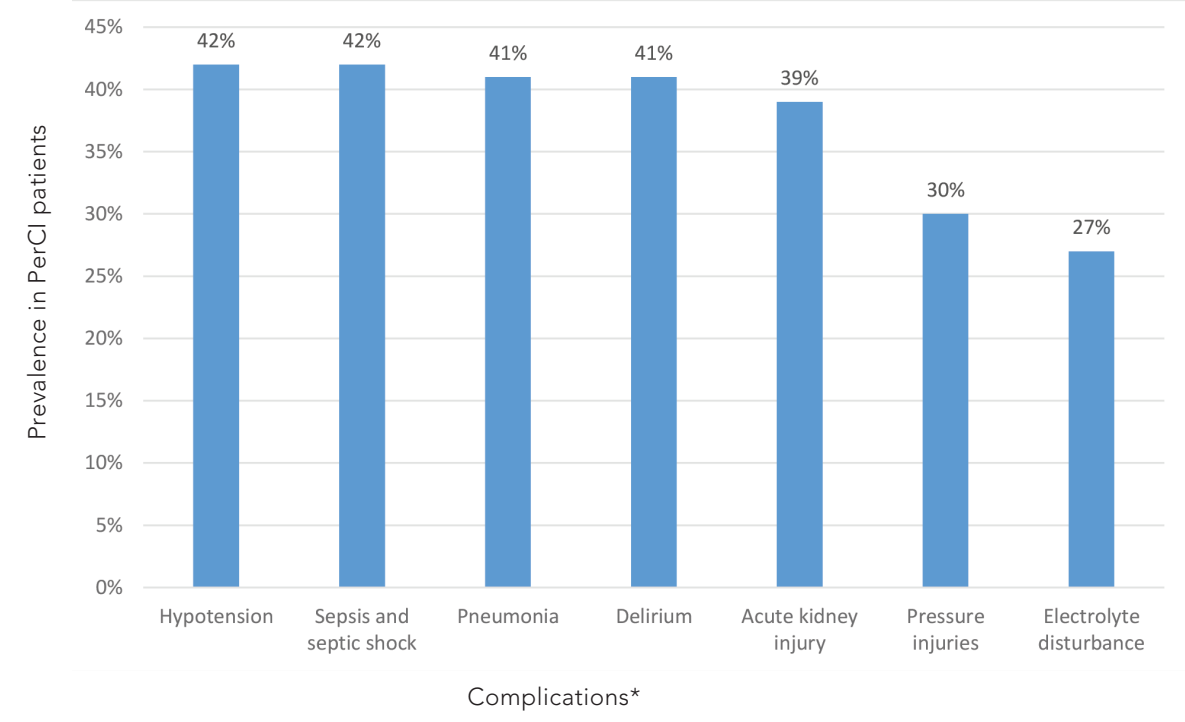

PerCl = persistent critical illness. * These are not mutually exclusive

documented complications. A smaller proportion of $\mathrm{PerCl}$ patients were discharged directly home from hospital.

In their aggregate, our findings indirectly support the view that the development of $\mathrm{PerCl}$ does not represent a mostly iatrogenic event but, rather, the expression of a more severe underlying original illness and more severe hospitalacquired complications. These complications in $\mathrm{PerCl}$ were neither resolved rapidly with medical intervention nor were they sufficiently severe to lead to early mortality. There may also have been hitherto unrecognised differences in ICU outcomes when treating particular pathologies at the time of hospital presentation,

coding. Such differences may well explain the increased rate of some coded complications in control patients. However, CHADx remains the most comprehensive instrument currently available to investigate hospital complications: it is unbiased, not amenable to investigator manipulation, and able to provide an electronic overview of complications in cohorts of patients admitted to hospital.

Finally, due to the nature of ICD-10-AM coding, and therefore for all patients other than the nested cohort, there was no capacity to identify the time of onset, severity and duration of complications, which may hold the key to determining progression to $\mathrm{PerCl}$ and therefore to patient outcomes.

\section{Conclusions}

In summary, we conducted the first comprehensive controlled assessment of the prevalence of coded complications among patients with PerCl and matched controls. We found that PerCl was associated with a threefold greater absolute number of complications. Moreover, a markedly higher proportion of PerCl patients underwent major ICU interventions including reintubation, tracheostomy and acute renal replacement therapy, with the rates of these remaining significantly higher after adjustment for exposure time. Hypotension, delirium and agitation, acute kidney injury, sepsis, pneumonia, pressure injuries, and metabolic and electrolyte abnormalities were the most common compared with ICU outcomes when treating the same pathologies arising later during the hospital admission.

\section{Competing interests}

None declared.

\section{Author details}

Boris Tseitkin'

Johan Mårtensson ${ }^{1,2}$

Glenn M Eastwood ${ }^{1,8}$

Alastair Brown ${ }^{1}$

Paolo Ancona ${ }^{1,4}$

Luca Lucchetta ${ }^{1,5}$

Theodore J Iwashyna ${ }^{6,7}$

Raymond Robbins ${ }^{3}$

Rinaldo Bellomo 1,8,9,10,11

1 Department of Intensive Care, Austin Hospital, Melbourne, VIC, Australia.

2 Department of Physiology and Pharmacology, Karolinska Institutet, Stockholm, Sweden.

3 Department of Administrative Informatics, Austin Hospital, Melbourne, VIC, Australia.

4 Department of Intensive Care Medicine, Catholic University of the Sacred Heart, "A. Gemelli" University Hospital, Rome, Italy.

5 Department of Anaesthesia and Intensive Care, IRCCS San Raffaele Scientific Institute, Milan, Italy. 


\section{ORIGINAL ARTICLES}

6 Department of Internal Medicine, University of Michigan, Ann Arbor, MI, USA.

7 Center for Clinical Management Research, VA Ann Arbor Healthcare System, Ann Arbor, MI, USA.

8 Australian and New Zealand Intensive Care Society Research Centre, Department of Epidemiology and Preventive Medicine, Monash University, Melbourne, VIC, Australia.

9 School of Medicine, University of Melbourne, Melbourne, VIC, Australia.

10 Data Analytics Research and Evaluation (DARE) Centre, Austin Hospital and University of Melbourne, Melbourne, VIC, Australia.

11 Department of Intensive Care, Royal Melbourne Hospital, VIC, Australia.

\section{Correspondence: Rinaldo.Bellomo@austin.org.au}

\section{References}

1 Iwashyna TJ, Hodgson CL, Pilcher D, et al. Timing of onset and burden of persistent critical illness. Lancet Respir Med 2016; 4: 566-73.

2 Carson SS. Definitions and epidemiology of the chronically critically ill. Resp Care 2012; 57: 848-56.

3 Kahn JM, Le T, Angus DC, et al. The epidemiology of chronic critical illness in the United States. Crit Care Med 2015; 43: 282-7.

4 Nelson JE, Cox CE, Hope AA, Carson SS. Chronic critical illness. Am J Respir Crit Care Med 2010; 182: 446-54.

5 Iwashyna TJ, Hodgson CL, Pilcher D, et al. Towards defining persistent critical illness and other varieties of chronic critical illness. Crit Care Resusc 2015; 17: 215-8.

6 Iwashyna TJ, Hodgson CL, Pilcher D, et al. Persistent critical illness characterised by Australian and New Zealand ICU clinicians. Crit Care Resusc 2015; 17: 153-8.

7 Australia and New Zealand Intensive Care Society; Centre for Outcome and Resource Evaluation. Adult Patient Database. https://www.anzics.com.au/adult-patient-database-apd/ (viewed Aug 2020).

8 National Centre for Classification in Health. International statistical classification of diseases and related health problems, 10th revision, Australian modification. Sydney: NCCH, 1998.

9 Jackson TJ, Michel JL, Roberts RF, et al. A classification of hospital-acquired diagnoses for use with routine hospital data. Med J Aust 2009; 191: 544-8.

10 Utz M, Johnston T, Halech R. A review of the Classification of Hospital-Acquired Diagnoses (CHADx) [Technical report No. 12]. Health Statistics Unit, Queensland Health; 2012. https:// www.health.qld.gov.au/_data/assets/pdf_file/0028/362845/ techreport_12.pdf (viewed Aug 2020).

11 Mira JC, Cuschieri J, Ozrazgat-Baslanti T, et al. The epidemiology of chronic critical illness after severe traumatic injury at two level-one trauma centres. Crit Care Med 2017; 45: 1989-96.

12 Ambrosino N, Venturelli E, Vagheggini G, Clini E. Rehabilitation, weaning and physical therapy strategies in chronic critically ill patients. Eur Resp J 2012; 39: 487-92.

13 Hollander JM, Mechanick JI. Nutrition support and the chronic critical illness syndrome. Nutr Clin Pract 2006; 21: 587-604.

14 Van den Berghe G, de Zegher F, Veldhuis JD, et al. Thyrotrophin and prolactin release in prolonged critical illness: dynamics of spontaneous secretion and effects of growth hormonesecretagogues. Clin Endocrinol (Oxf) 1997; 47: 599-612.

15 Scheinhorn DJ, Hassenpflug MS, Votto JJ, et al. Post-ICU mechanical ventilation at 23 long-term care hospitals: a multicenter outcomes study. Chest 2007; 131: 85-93.

16 Kalb TH, Lorin S. Infection in the chronically critically ill: unique risk profile in a newly defined population. Crit Care Clin 2002; 18: $529-52$.

17 Nelson JE, Tandon N, Mercado AF, et al. Brain dysfunction: another burden for the chronically critically ill. Arch Intern Med 2006; 166: 1993-9.

18 Carasa M, Polycarpe M. Caring for the chronically critically ill patient: establishing a wound-healing program in a respiratory care unit. Am J Surg 2004; 188: 18-21.

19 Schulman RC, Mechanick JI. Metabolic and nutrition support in the chronic critical illness syndrome. Resp Care 2012; 57: 958-78.

20 Van den Berghe G, Wouters P, Weekers F, et al. Intensive insulin therapy in the critically ill patients. N Engl J Med 2001; 345: 1359-67.

21 Van den Berghe G, Wilmer A, Hermans G, et al. Intensive insulin therapy in the medical ICU. N Engl J Med 2006; 354: 449-61.

22 Nierman DM, Mechanick JI. Bone hyperresorption is prevalent in chronically critically ill patients. Chest 1998; 114: 1122-8.

23 Nelson JE, Meier DE, Litke A, et al. The symptom burden of chronic critical illness. Crit Care Med 2004; 32: 1527-34.

24 Girard TD. Brain dysfunction in patients with chronic critical illness. Respir Care 2012; 57: 947-55.

25 Silber JH, Romano PS, Rosen AK, et al. Failure-to-rescue: comparing definitions to measure quality of care. Med Care 2007; 45: 918-25.

26 Maguire, JM, Carson, SS. Strategies to combat chronic critical illness. Curr Opin Crit Care 2013; 19: 480-7.

27 Damuth E, Mitchell JA, Bartock JL, et al. Long-term survival of critically ill patients treated with prolonged mechanical ventilation: a systematic review and meta-analysis. Lancet Respir Med 2015; 3: 544-53. 